\title{
Confronting social policy challenges in Fiji
}

\author{
John Cameron
}

\section{Introduction}

Every society has ways of distributing social and economic uncertainty and insecurity within and between individuals, groups of individuals and institutions. The basis of this distribution is not random but rather is a result of a set of historically constituted processes that shape a society's institutions and its people's beliefs, motivations and aspirations. Social policy is an intervention by the state designed in general to alter this distribution and, more specifically, to redistribute and ultimately reduce the experience of uncertainty and insecurity. A critically important way by which social policy can reduce the experience of uncertainty and insecurity is through a reduction in the degree of inequality found within a society. In fostering socioeconomic security through a greater degree of equality within a society, state social policy represents an investment in the trust which underpins 'social wealth' and which builds an inclusive polity.

Fiji had a per capita GNP of over US $\$ 2,000$ in the mid 1990s (World Bank 1995a). Further, with a comparatively long life expectancy, comparatively low infant mortality, and comparatively high adult literacy, Fiji had a reasonably satisfactory level of social development relative to its income. Despite this, however, Fiji did not have a socially inclusive polity. Notwithstanding a rich history of strong civil society actors and institutions, for most of the post-independence period state policy has been shaped by an élite which has used ethnic 
identity as the basis for political mobilisation (Sutherland, this volume). The 'politics of ethnicity' have not been able to foster trust between the archipelago's two major ethnic groups, in large part because state social policy has sought to redistribute social and economic uncertainty and insecurity between ethnic groups, to the detriment of one group, the Indo-Fijian community, in an effort to deliberately maintain the pre-independence policy framework of 'separate development'. A major consequence of such a policy framework has been to foster inequality and social exclusion, both between and within the indigenous Fijian and the Indo-Fijian communities.

It was only for a brief period during the mid 1980s that the policy framework that fostered inequality and social exclusion was challenged. During a period of multidimensional crisis, social demands based upon regional, class, gender and environmental conditions led to the formation of the Fiji Labour Party (FLP) and the call from those who had been excluded from élite politics for the construction of a less unequal, socially-inclusionary, multicultural polity which systematically confronted the deeper problems of ethnic tension, developmental values and dysfunctional economic tendencies. This call was however cut off by the 1987 military coups, which violently reasserted the primacy of the politics of ethnicity.

Despite this, the call for a more inclusive polity did not disappear. Indeed, at the end of the 1990s it is being reactivated. The new constitutional settlement explicitly recognises the need to construct a less unequal, socially inclusionary multicultural polity in Fiji (Ghai, this volume). The overwhelming victory of the FLP in the 1999 general elections demonstrates the extent to which the call for a more inclusive polity has deep roots within Fiji society. This is because ethnic tension and contradictory development processes have not disappeared; neither have claims based upon regional, class, gender and environmental conditions. In the construction of such a polity, the social policy of the state has a pivotal role to play. The redistribution of social and economic uncertainty and insecurity by the state must be done in a way which complements and augments the strengths of a diverse civil society, and in so doing develops the trust-and most particularly the inter-ethnic trust-which can improve the quality of people's lives in Fiji. 
This chapter examines some of the major strategic issues in Fiji confronting social policy. A fundamental proposition of the chapter is that Fiji society was diverted from important debates about the fundamentals of social policy by the coups of 1987. Confronting the future of social policy would thus benefit from looking to the past. Looking back, it is clear that there remains a major challenge confronting civil society and the state in seeking to redistribute social and economic uncertainty and improve the degree of equality within society, and in so doing build social wealth in Fiji. In the next section, the neoliberal approach to social inequality and hence social policy is critically assessed and the new institutional economics (NIE) introduced as a countervailing approach rooted in distinctive moral and political perspectives which emphasise the interaction between civil society, state institutions and imperfect markets in facilitating improvements in the degree of equality within a society. In light of this framework, the third section examines the material reality of social inequality in post-colonial Fiji. It is argued that the challenge confronting the state is not in the detail of policy design but rather in the need to build on and invest in existing social wealth so as to institutionalise positive socioeconomic processes. The fourth section illustrates how this might be done by briefly examining three possible fields of policy which require the institutionalisation of positive socioeconomic processes, namely health and nutrition, education and community relations. The final section offers some conclusions.

\section{Neoliberal ideology, social policy and the NIE}

For most of the past two decades socioeconomic development thinking has been fundamentally neoliberal in outlook. From a neoliberal perspective, inequality between individuals in both potential and outcome is the natural condition of humanity. The primary cause for this innate inequality may be either genetic potential or the mysterious ways of a divine creator. In either instance, as members of the species are observed to be different they will therefore be doomed to be unequal in socioeconomic experience.

This view of society is found in Western liberal philosophy. It is consistent with the theorems of neoclassical economics concerning efficiency, equity and stability. The conclusions from such analysis, stressing a condition of 'natural' inequality, is that societies are best 
organised for the social good on the basis of equal rights to individual voluntary contracts negotiated in free markets. The resulting allocation of resources, including inequality in control over resources between individuals, households and nations, will reflect unequal abilities and efforts in contributing to meeting others' desires, and the strength of one's own preferences for possessing scarce goods and services. The resulting distribution may thus be said to be equitable, albeit in a limited sense. Granted, some neoliberals go further, recognising that equality of contract requires equality of opportunity. They thus become advocates of equality in access to education, health and recruitment through merit-based procedures. Some may also show concern on the question of the right to inherit material wealth. Nonetheless, the argument that any form of deprivation rooted in social inequality demands collective action, in the shape of allocating resources towards the deprived, is marginalised by most neoliberal thinkers. The neoliberal view does not rule out individual altruistic, charitable actions as the philosophical basis for social policy: indeed, it highlights them.

Recent emphasis in the development literature on the need to encourage growth in 'human capital' demonstrates the dominance of neoliberal thinking. Human capital is most easily applied to individuals; thinking about relationships between individuals and between groups of individuals is peripheral. Thus, inequality is not relational; it is the outcome of inadequate 'investment' by the individual or the individual's 'agent' in developing their own capacities. Human capital is thus, in its emphasis on the isolated individual, very much a product of neoliberal thinking.

The introduction of the concept of 'social capital' recognises this deficiency, highlighting as it does the importance of both the quantities and qualities of relationships in the development process. However, social capital also has problems: in particular, the implicit application of quantification to non-material phenomena betrays its neoliberal origin. Therefore, an alternative concept can be proposed: social wealth. Social wealth is centrally concerned with the degree of trust in a society, a trust which is established on the frontier where culture, politics and economics intersect. Social wealth is the outcome of 'the form of norms of reciprocity and networks of civic engagement' (Putman 1993:167) which facilitate the coordination of action within 
societies. Clearly, in order to be able to coordinate action, such norms must build trust. This concern with trust can lead to an analysis of the distribution of insecurity as a social phenomenon restricting trust and, in so doing, fostering a degree of inequality within a society. Indeed, although every society has ways of distributing social and economic insecurity, it is rare for the distribution to be egalitarian. Thus, inequality is a social phenomenon. Social policy can then, as already noted, be broadly conceptualised as being centrally concerned with how the state acts to reduce and redistribute uncertainty and insecurity and in so doing reduce the degree of inequality within a society.

The all too apparent failure of neoliberalism to remove uncertainty, insecurity and inequality from the lives of people means that there is a need to develop a new policy agenda. This policy agenda should be based upon a countervailing philosophy rooted in distinctive moral and political perspectives and yet qualified by an element of hardheaded, rather than hard-hearted, economics. It can be suggested that the NIE could provide the basis of such a countervailing philosophy. The essential aspects of NIE which have attracted development economists can be summarised as being: an assumption that the operation of market forces has to be understood in a long term, institutional context; an assumption that changing civil society institutions can have high transitional costs; and a profound doubt regarding neoliberal claims that open markets guarantee efficiency, equity and stability, in large part because of bounded rationality, public goods, risk and uncertainty, and moral hazard, all of which facilitate the emergence in open markets of informational deficiencies.

The NIE generates an economics that emphasises the interaction between civil society, state institutions and markets (Harriss, Hunter and Lewis 1995). Moreover, in this interaction, state institutions are critical. State institutions can, by investing in social wealth, reduce inequality, strengthen civil society, and in so doing facilitate better outcomes from imperfect markets. Using the NIE and an emphasis on social wealth as the theoretical basis for state intervention thus requires understanding the historically-constituted processes shaping a society's institutions, its pattern of inequality, and its social wealth: the beliefs, motivations and aspirations of its people. The details of such an account are clearly beyond the scope of this chapter. Nonetheless, it can act as an organising framework to guide the analysis that follows. 


\section{The material reality of inequality in Fiji}

Fiji came to political independence in 1970 with a discriminatory pattern of policy priorities that had been set by the colonial regime. However, both major ethnic groups had, to an extent, sought to bypass the policy priorities of the colonial state. Within both the indigenous Fijian and the Indo-Fijian communities there was a long history of active civil societies fostering the development of non-market socioeconomic relationships and in so doing deepening the formation of social wealth. This social wealth facilitated self-provisioning in the areas of health care, education and social security. Thus, an extensive network of self-provisioning in health, education and social security was maintained and indeed deepened during the colonial period. This self-provisioning was crucial to the quality of lives of the most vulnerable people in Fiji prior to independence.

The 1970s can be characterised as a decade of progress in equalising the terms and conditions under which the forms of state social provision inherited from the colonial period could be accessed. State institutions, particularly those delivering social policy interventions, were reformed and expanded, and much space was left to civil society and its institutions, which utilised the strong social wealth within both of Fiji's two main communities. This was accompanied by significant investment in infrastructure and the reform of taxation structures, which, along with institutional reform, removed some of the worst elements of the colonial inheritance.

Nonetheless, by the start of the 1980s significant inequalities remained. Income inequalities between the indigenous Fijian and Indo-Fijian communities, to the benefit of the latter, were well documented (Sutherland 1992). So too were the income inequalities between men and women. However, as in other societies, the experience of inequality went beyond the monetary. The impact of state and civil society-led efforts to address non-monetary inequality were indirectly assessed in the early 1980s, when a program of research was undertaken to assess the adequacy of using 'active life profiles' (Seers 1977) as a means of integrating social analysis and planning under varying national conditions. As part of this program, a country study was carried out in Fiji (Cameron 1987a).

Active life profiles are non-monetary indicators of social development. They seek to show how, for a specific group of people at a point in time, life expectancy can be broken down into a set of 
activities that will be conducted over a life. In order to do this, life is first broken down into a set of mutually exclusive activities, or 'states of life'. The states of life considered in this chapter are those generally collected in national population censuses under the three headings of education, forms of economic activity and forms of economic inactivity. Demographic data provide links between these states of life. The proportion of people in a particular state of life are subdivided by age and then each age weighted by the average chance at birth of a person being alive at that age. Such weighting enforces consistency in the calculation. The results allocate a number of years to each state of life, and because the states of life are mutually exclusive the weighted sums will add up to life expectancy at birth. The expected duration in any state thus depends on the frequency of other states and a hidden state, that of being dead. A comparison of states of life across different groups can then be used to assess socioeconomic patterns and the general development status of a group of people.

By way of example, Table 6.1 presents the active life profiles for men in Fiji's two main ethnic groups around 1980. Table 6.1 demonstrates that around 1980 out of a life expectancy of 65.83 years for indigenous Fijian males, some 19.67 years would, on average, be spent as a villager or as a family worker. By way of contrast, amongst

\section{Table 6.1 Active life profiles in years for men in Fiji around 1980}

\begin{tabular}{|c|c|c|c|}
\hline State of life & All Fiji males & Indigenous Fijian & Indo-Fijian \\
\hline $\begin{array}{l}\text { Pre-school and } \\
\text { in education }\end{array}$ & 16.35 & 16.10 & 16.36 \\
\hline $\begin{array}{l}\text { Villager and } \\
\text { family worker }\end{array}$ & 10.54 & 19.67 & 2.64 \\
\hline $\begin{array}{l}\text { Own business, including } \\
\text { sugar cane farming }\end{array}$ & 9.73 & 5.42 & 14.42 \\
\hline $\begin{array}{l}\text { Employed by private } \\
\text { employer }\end{array}$ & 12.13 & 9.13 & 13.52 \\
\hline Employed by government & 7.10 & 7.70 & 6.31 \\
\hline $\begin{array}{l}\text { Inactive, unemployed, } \\
\text { retired, unknown }\end{array}$ & 8.01 & 7.33 & 8.04 \\
\hline $\begin{array}{l}\text { Life expectancy at } \\
\text { birth }\end{array}$ & 63.86 & 65.83 & 61.61 \\
\hline
\end{tabular}

Source: Cameron, J., 1987b. 'Fiji: the political economy of recent events', Capital and Class, 33:32. 
Indo-Fijian males, out of a life expectancy of 61.61 years, some 14.42 years would be spent, on average, engaged in their own business, including sugar cane farming.

The research carried out in Fiji documented the material reality of social inequality between the two main ethnic groups in the early 1980s. The research found that Fiji possessed the demographic and educational characteristics of a relatively developed country. This applied to the population as a whole, both major ethnic groups, and sexes. At the same time, the research found that the difference in the relative position of the two major ethnic groups in terms of average money-equivalent incomes was offset by differences in their relative position in terms of active life profiles. Thus, inequality between the ethnic groups in active life profiles ran against inequality in monetary terms, to the benefit of the indigenous Fijian community. A complacent conclusion might have been that the socioeconomic positions of the two main ethnic groups in Fiji were merely different, and not fundamentally unequal. However, the reality was more complex: while income was only one factor in inequality, the impact of other factors which might have been thought to offset monetary inequality, were in fact differentiated along clear lines.

The research therefore considered in detail the components of the active life profiles, as indicators of inequality amongst groups in Fiji. Considering first data on education and economic activity for indigenous Fijians and Indo-Fijians, it appeared that both groups had a similar expected duration of education. This is demonstrated, for example, in Table 6.1 for males. This equality was however offset by dissimilarity when life cycles in patterns of economic activity were considered. A key difference existed between the communities in terms of their involvement in rural economic activities. Indigenous Fijians could expect a longer duration in rural economic activities where the individual exercised some explicitly recognised control over their life. Moreover, indigenous Fijians could expect a shorter duration of economic inactivity. Both are demonstrated in Table 6.1 for males. In large part, this dissimilarity might have been due to the term 'villager' being exclusively applied to indigenous Fijians in the census data that formed the basis of the construction of the active life profiles. The exclusive assignation of this category did capture some important attributes of indigenous Fijian rural life, in terms of strong communal rights and obligations involving agricultural and non-agricultural 
production and the distribution of produce. Indigenous Fijian life, by combining virtually equal access to education when compared to that obtained by Indo-Fijians, a longer expected duration in economic activities where the individual exercised some explicitly recognised control over their life, a shorter expected duration of economic inactivity, and a longer life expectancy, might have appeared to have had a higher quality of life and less inequality than that experienced by Indo-Fijians. This apparently higher quality of life amongst indigenous Fijians could be clearly contrasted with that of IndoFijians, many of whom, having been involved in monocultural sugar cane production, homestead production for self-provision, or being economically inactive in agriculture, faced different relationships in agriculture as well as in private sector non-agricultural activity.

In terms of gender-based differentials, the research on education and economic activity demonstrated that the expected duration of schooling for males and females in Fiji during the 1970s was virtually identical (Cameron 1987b). At the same time, women in Fiji had a life expectancy at birth seven years greater than men in the early 1980s. Lower infant mortality rates for females were important in explaining part of this difference; however, lower age-specific death rates were found for women at most ages when compared to men. Nonetheless, women faced a disadvantaged position. In terms of economic activity, including declared unemployment, women had an expected duration of economic activity which was only a fraction of that for men, although indigenous Fijian women had a higher expected duration of economic activity than Indo-Fijian women. Clearly, men stood between women and economic activity. This difference was reflected in the very large variation in the expected duration of economic inactivity between men and women; women could expect substantially longer periods of inactivity. It is however worth reinforcing the point that ethnic differences existed within women. Indo-Fijian women were disadvantaged in comparison with indigenous Fijian women, through having shorter lives, less control over their economic activities, and lower money-equivalent incomes.

Gender-based differences in economic activity and inactivity in part reflected the way in which the census data collected in the 1970s, which formed the basis of the information used in the construction of the active life profiles, 'pushed' women into the economically inactive category. As elsewhere, women in Fiji have multiple economic roles. 
Census questions in the past tended to seek to find a unique role. In these circumstances, when a person was asked whether their single role was looking after children, tending livestock, maintaining crops, selling vegetables, participating in community projects, going fishing or seeking waged work, it was not surprising that priority was attached to childcare- a category deemed in most censuses to reflect economic inactivity. However, for women, economic inactivity did not mean leisure but rather repetitive unremunerated domestic work in the service of others, including husbands, children and kin networks. The small number of women credited in the census as family workers and villagers compared with men supports the suggestion that women's work was inadequately recognised in the censuses of the 1970s. Thus, the long expected duration of economic inactivity for women did not reflect freedom to choose.

Inequality in Fiji in the post-independence period was thus multifaceted. It could exist in monetary or non-monetary dimensions. The way in which it existed in these two dimensions could be either mutually reinforcing or offsetting. The pattern of inequality also differed on the basis of certain group characteristics: whether someone was male or female, rural or urban, indigenous Fijian or Indo-Fijian. The research had clear implications for social policy: there was an obvious need to be sensitive to differences in patterns of life between Fiji's two main ethnic groups while at the same time using common principles to be even-handed in resourcing the differing needs of indigenous and Indo-Fijians.

This pattern of inequality did not significantly change during the 1980s. During the early 1980s Fiji underwent a multidimensional crisis. Economic indicators were moving violently as a consequence of the second major oil price rise and major fluctuations in the world market price of sugar. Environmentally, the impact of a year of drought was compounded by cyclone Oscar early in 1983; both had mutually reinforcing negative consequences for the sugar crop, the economy and thus for inequality.

The multidimensional crisis damaged the process of social development in Fiji. Studies of poverty in the early 1980s suggested that there were roughly equal proportions of vulnerable people in both ethnic groups, though the risk of deep poverty may have differed between the two groups (United Nations Development Programme/ Government of Fiji 1997). Thus, both major ethnic groups had, as in 
the 1970s, broadly comparable experiences of socioeconomic deprivation and inequality, although this must be qualified by the recognition that specific differences in monetary income, economic activity, economic inactivity and non-monetary indicators were, as in the 1970s, real.

The crisis demanded confident leadership; however, the Fiji government was unable to provide such leadership. In 1982 Fiji's socioeconomic development started to be governed by the dictates of neoliberalism. The failure of the government to provide confident leadership signalled the end of the independence 'honeymoon', exposed the ideological bankruptcy of the 'Pacific Way' as an innovative development strategy and facilitated the emergence of claims based upon regional, class, gender and environmental conditions. At the heart of these claims lay a common set of demands: for an end to an élite-dominated, socially exclusionary politics based upon ethnic mobilisation; and for the construction of a less unequal, socially-inclusionary multicultural polity in Fiji.

The 1985 Fiji Trades Union Congress annual conference was a vital event in the process of the formation of the FLP as an organised expression of such demands. The FLP was not only needed to halt the erosion of the hard-earned rights of organised labour, but also to represent the demands of wider interests seeking to challenge the dominant status quo. This challenge had strong social policy implications: the emergence of the FLP helped to initiate a societywide debate on the future of multicultural relations in Fiji, and, more particularly, the way in which social policy could be configured so as to facilitate a less unequal, socially-inclusionary multiculturalism in Fiji.

The previously predominant politics of ethnicity offered a fundamental challenge to those who sought to justify broad-based interventionist social policies designed to reduce inequalities in wealth, income and consumption, and to encourage the full expression of the capabilities of all citizens. The politics of ethnicity were however violently reasserted in 1987. It is not surprising that neoliberalism in Fiji was solidified during a period when the politics of ethnicity were being violently reasserted. With its explicit acceptance of 'natural' difference, neoliberalism is consistent with any politics that emphasises difference; thus, neoliberalism has clear affinities to the politics of ethnicity. 
While both major ethnic groups could draw on histories of nonmarket socioeconomic relationships rooted in active civil societies and deploying strong social wealth to provide education, health care and social security, neoliberal development strategies since the early 1980s may have undermined those aspects of civil society and social wealth that emphasised non-market relationships and guaranteed access to basic needs (Barr 1990; United Nations Development Programme/ Government of Fiji 1997). At the same time, anti-poverty social policy was very weak in the 1980s, in large part because neoliberal ideology both 'naturalises' difference and questions the efficacy of intervention. Thus, neoliberal development strategies since the early 1980s increased inequality and poverty between and within both ethnic groups.

\section{The challenge for social policy}

The 1990s have witnessed a sharp intensification of the politics of identity around the world. In many cases, greater sensitivity to the politics of diversity has been beneficial by increasing awareness of the need for socially inclusive policies: for example, increased consciousness concerning the social impact of gender relations. However, this need not be the case. The increasing politicisation of ethnicity within Fiji during the 1980s has meant that dissent and conflict are commonly rooted in the identity politics of ethnicity. The politicisation of ethnicity cannot produce uniform and predictable outcomes. It is therefore clear that the management of ethnic diversity in Fiji remains the major challenge for the next millennium. Social policy has a major role to play here. In that social policy is an intervention by the state designed in general to alter the distribution of social and economic insecurity, a critically important way by which social policy can reduce the experience of economic insecurity is through a reduction in the degree of inequality found within Fiji. In fostering socioeconomic security, social policy can build trust which can in turn help create the foundations of a new pattern of multicultural relations-one which recognises difference while noting common ground. Moreover, social policy can provide, or not provide, resources to challenge and change already-existing patterns of multicultural relationships.

The challenges that the state in Fiji confronts in social policy are not those of detail. Social policy must confront the deeper problems of ethnic tension and contradictory developmental values. The challenge 
now is thus to develop a social policy that complements and augments the strengths of those civil society institutions which remain strong despite more than a decade of neoliberalism. The state needs to institutionalise positive socioeconomic processes which build upon existing social wealth in order to develop a less unequal, sociallyinclusive society with higher levels of trust and an improved quality of life for the people of both ethnic groups. Meeting this fundamental challenge will contribute to eradicating poverty, ill health, and insecurity. This challenge demands much of the state in terms of creating an atmosphere for new interventions. Clearly, the agenda facing the new government is large. Space precludes detailed consideration of the breadth of interventions that could contribute to eradicating insecurity and building a socially inclusive society. Rather, three areas where new interventions would be welcome can be briefly discussed. These three areas are health and nutrition, schooling and community relations.

\section{Health and nutrition}

The relationship between undernutrition and poor health status has been emphasised in international conferences and is widely accepted as a 'stylised fact' (Asian Productivity Organisation 1991). However, the availability of sufficient calories is neither a necessary nor a sufficient condition to break the link between diet and ill health. This is because the way in which diets change in the process of development can be a major cause of ill-health (Bonnemaison 1978; Thaman 1983; Cameron 1991). This has been the case in the South Pacific in general, and Fiji in particular, since the late 1970s.

Fiji's Eighth Development Plan was the first plan to highlight the 'promotion of proper nutrition' (Fiji Central Planning Office 1980:267) as the first priority of health policy. The 1980s saw some efforts in nutritional education as part of health policy. In practice, however, health policy in general and nutritional policy in particular has been uneven, primarily in terms of its spatial distribution, but also in terms of its impact on lower income households, as under neoliberalism market forces have been used increasingly to allocate access to nutritional and health care resources.

The increasing resort to market forces, particularly in the allocation of access to nutritional resources in Fiji, has resulted in a dietary and lifestyle revolution over the past 20 years. This revolution has brought 
with it a number of health problems that resemble those of richer economies, and particularly the significant increase in vulnerability to diseases linked to diet. The source of these problems is not however undernutrition. Rather, it is the contradictory articulation of unbalanced diets and overnutrition as the allocation of access to nutritional resources has become market-led. Unbalanced diets and overnutrition imply a different set of issues than those conventionally found in developing countries. In particular, it implies that poor nutritional status can exist side by side with good nutritional status, and that different policies are required to deal with the two sets of issues.

In the case of poor nutritional status, an association between high food imports and low status can be observed and positively links economic policies, health policies and nutritional policies. A crosssection of the overall level of Fiji's food imports in the 1980s showed a relatively high level of food imports, expressed in US dollars per capita per year. Under neoliberalism, the ratio of food imports per capita has increased. More imported food generally means a diet consisting of greatly increased proportions of refined sugar and saturated fats from both fatty meat and dairy products, with an associated higher energy intake. But more energy and less dietary fibre, in conjunction with the reduced physical activity associated with urbanisation, places stress on the body and can produce ill health, lower productivity and, in general, a lower quality of life.

Granted, if diets prior to the increase in the intake of imported food had contained little animal-derived protein or were highly restricted in the variety of foods on which they were based, then the 'gastronomic transition' might have had some desirable nutritional effects, which may in turn have offset some of the undesirable ones. However, except in the extreme conditions of natural disaster, there is no reason to believe that people living in such a biodiverse environment as that found in Fiji were regularly deprived of energy or protein. In these circumstances, few food imports are in any sense nutritionally 'essential'. An argument can therefore be made in favour of reducing food imports. Health and nutrition policy would then have a trade impact, by discouraging the use of low quality imported food and returning to greater self-provisioning, a return that would be predicated upon deepening investment in social wealth. Indeed, the peoples of Fiji, of both major ethnic groups and all income levels, 
have, by not making full use of the capacity of their environments to provide healthy diets, unnecessarily high risks of ill health. However, self-provisioning should not be taken to mean exclusively communitybased production. Self-provisioning can also have a regional and a national dimension; indeed, it must have this dimension if it is to foster the development of social wealth between the two major communities in Fiji.

Two possible policy options exist which would increase the ratio of self-provisioned food. The first would be to ban or impose quotas on imported items which were judged to be actually harmful nutritionally; this should not be ruled out, although it is up to nutritionists to make the case in Fiji. The second would be to raise duties differentially over time in a manner that took account of food consumption, nutritional status and agricultural production. Either policy option implies that decisions in the agricultural sector, and macroeconomic policy more generally, will impact upon the nutritional choices available and thus the overall health of the population.

The problem of unbalanced diets has a health impact. In Fiji there has been some evidence of various forms of child malnutrition, notably around weaning, indicating the need to buttress nutrition policy with the promotion of breast feeding and adequately resourced, easily accessed, primary health programs (Barr 1990). There has been much useful experience in innovative primary health care in the public and non-governmental sectors within the South Pacific region. Best practices need to be examined and assessed for their transferability. At the same time, the nutritional well being of adults in both the indigenous Fijian and the Indo-Fijian communities is also a concern. Adult malnutrition may be associated with a number of disorders, such as diabetes, hypertension, cardio-vascular disease and gout (Barr 1990).

Some of these adult diseases are, it must be admitted, also a function of overnutrition. In part, overnutrition has occurred because the peoples of Fiji have not been making full use of the capacity of their environment to provide healthy diets suitable to their cultural, and possibly physiological, potential. At the same time however the social and political upheavals of the last decade may have contributed to self-induced ill health. The possibility of self-induced ill health and its related health care costs suggests a peculiar variation on the syndrome described by Illich in the 1970s (Illich 1976). In this view, changes in diet can be a reflection of more general cultural, economic 
and ecological pressures. These pressures have an impact on nutritional status, giving rise to phenomena such as alcohol abuse, the early cessation of breast-feeding, and other problems associated with 'modernisation'. These pressures are recognisable in many societies. The policy response has to be multidimensional, involving agricultural, macroeconomic, health, education and social policy. The response also raises global issues involving the regulation of transnationals involved in the agro-food sector.

Nutrition has in general not been a resource priority for the public sector. This must change. Health and nutrition policies in the complex mix of environments of Fiji will only be effective when the objectives, targets and strategies of such policies are adjusted to the conditions and needs at the country, regional, provincial, island, municipality and village level. This in turn requires a continuous dialogue between the various levels of government on all aspects of food production, distribution and consumption. There are international models of interactive, community based approaches to social policy formation which might be relevant to the country in this regard.

Dialogue has not been the rule in the past. Specific policy development for nutrition was in the past largely allocated to the Food and Nutrition Committee, which brought together civil servants from various ministries plus representatives of non-governmental organisations and academics with interest in the health field. It can be argued that Fiji's Food and Nutrition Committee needs to be relaunched in order for it to take greater responsibility for coordinating nutrition interventions. For this to work, it is crucial that there are opportunities for people to comment systematically on program and project proposals, not only in the health field but also in the broader sphere of agricultural and marine resource development. In part, this is because in the longer term sustaining access to a nutritious diet means sustaining the environment within which that diet is produced.

\section{Education}

In order to foster the emergence of a less unequal, socially inclusive polity, there is a need to develop new approaches to Fiji's school curriculum. Four concepts should be integrated as core principles into Fiji's school curriculum: anti-racism, multiculturalism, global 
citizenship and sustainable development education. In terms of the first two concepts, a lively debate has been conducted in the education field over the philosophical relationship between anti-racist and multicultural education (Foster 1990; Troyna and Hatcher 1992). This debate can be understood to have been centered on the challenge of presenting anti-racism as a universal, moral obligation for everyone, alongside a multicultural approach emphasising an element of moral relativism within a society. Anti-racism and multiculturalism can be considered to be consistent with the concept of global citizenship, which stresses universal political equality and thus has clear affinities with anti-racism and multiculturalism. Sustainable development education as a concept stresses the role of structural economic factors in fostering social inequality, as well as the impact of choices of technology in contributing to or restricting ecological degradation.

Putting these issues into a formal curriculum context involves differing disciplinary emphases. The demands of multicultural education in schools can be understood as falling primarily upon the arts and humanities, while anti-racist education looks to politics and an element of biology. Global citizenship education requires a basis in environmental science and peace studies, while sustainable development education puts a stress on economics with an element of geography. Experience suggests that multicultural and global citizenship issues as wholly positive, universal concepts may be well understood by younger children. Anti-racism and sustainable development education are more complex concepts. Their more subtle relativistic considerations may be best handled from more local, immediate, experiential starting points which look towards older children and adult education.

Despite the fact there are clear practical problems with handling the four concepts in one consistent framework, the shared values of all the concepts suggests that integrating them into one framework suitable to the specificities of Fiji offers an important challenge to Fiji's educationalists. However, the need to raise the profile of anti-racist, multicultural, sustainable development and global citizenship education within an integrated school curriculum in Fiji can only yield full benefits if even the most committed school staff are adequately resourced and supported by a multicultural, anti-racist ethic in social policy at national government level. 


\section{Community relations}

Community relations in Fiji turned violent in the 1980s, in part because of a growing criminalisation of urban young men who demonstrated especially violent individual behaviour. Moreover, since 1987 there was a marked increase in the risk of collective violence. The major contributory factor to this deterioration in community relations was the increase in the social acceptability of violence, primarily as a result of the activities of the state in legitimising arbitrary violence. The increased politicisation of ethnicity meant that the potential for violence increased, and powerful interests sought to promote intercommunal hostility. However, it should be stressed that while the potential for violence has increased in the last decade, Fiji has been atypical in that there has been only a limited recourse to the use of violence in civil society. Nonetheless, it remains the fact that there are now larger numbers of men who are ideologically and technologically equipped to engage in violent action. Positive action to reduce the potential for violence is needed as a social policy priority.

In order to reduce the potential for violence, social policy in Fiji needs to be pro-active in building bridges between the two major communities. There is much that can be done in Fiji in developing means of communication and indicators that allow patterns of whole lives, including experiences of coercion and deception, to be understood sensitively at all levels of aggregation and in a way which omits no sub-group of people. Communicating the patterns of the lives of others to people remote from that experience is needed if community relations are to improve. Facilitating unstructured, mutually reflective cultural contact has a role to play in this regard.

\section{Conclusion}

Neoliberalism has been dominant in Fiji since 1982. This approach to development 'naturalises' inequality and fosters a degree of social exclusion which, in a divided society, can serve to maintain the status quo. Fiji, both prior to and during the period of neoliberalism, had at best limited success in reducing inequality. This limited success can be easily understood: civil society, social wealth and the NIE constitute a framework that asks questions about the effectiveness of market forces as guarantors of socioeconomic development. At the same time, from the mid 1980s up to and including the 1999 general elections, there 
have been challenges to inequality and social exclusion in Fiji. Granted, Fiji's history of strong civil society institutions in both major ethnic groups has facilitated social wealth formation and a good quality of life for many of Fiji's people. Nonetheless, challenges remain. The construction of a less unequal, more socially-inclusive, multicultural polity requires that state social policy actively support civil society institutions in both major communities involved in the self-provisioning of healthcare, education and social security, while at the same time augmenting those institutions in a manner conducive to reducing inter-community inequalities and increasing trust. Social policy in health and nutrition, education and community relations can help in this regard.

The people of Fiji still have exceptional room for maneuver with respect to their stocks of social wealth and natural capital. A future, progressive social policy could seek to ensure that all people in Fiji have sufficient knowledge and trust in each other to forego the possibility of inter-community violence. This requires that all people derive sufficient income to sustain themselves in good health, that the degree of equality within the country be increased, while at the same time bequeathing sufficient natural capital to future generations to meet the objectives of both local and global sustainability. Fiji was an example to the world in the 1970s, produced a promising indigenous socio-political movement in the 1980s, has stepped back from the brink of breakdown in the 1990s, and could become a leader in the construction of a more equal, socially-inclusive, multicultural polity. To do this requires a major rethink of the strategic objectives of state social policy, to which this chapter has been addressed. 
This text is taken from Confronting Fiji Futures, edited by A. Haroon Akram-Lodhi, published 2016 by ANU eView, The Australian National University, Canberra, Australia. 